\title{
Beliefs about antipsychotic versus hypoglycemic medications among individuals with serious mental illness and type 2 diabetes
}

This article was published in the following Dove Press journal:

Patient Preference and Adherence

8 May 2012

Number of times this article has been viewed

Jennifer MAakre'

Deborah R Medoff' ${ }^{1,2}$

Lisa B Dixon ${ }^{1,2}$

Julie A Kreyenbuhl ${ }^{1,2}$

IVA Capitol Healthcare Network Mental Illness Research, Education, and Clinical Center, Baltimore VA Medical Center, ${ }^{2}$ Division of Services Research, Department of Psychiatry, University of Maryland School of Medicine, Baltimore, MD, USA
Correspondence: Jennifer Aakre Baltimore VA Medical Center, 209 West Fayette St (VA Annex), Baltimore, MD 2I20I, USA

$\mathrm{Tel}+\mathrm{I} 4106371877$

Fax + I 4106057739

Email jennifer.aakre@va.gov
Background: This study compared the beliefs held by individuals with coexisting serious mental illness and type 2 diabetes regarding the necessity and risks of taking antipsychotic versus hypoglycemic medications. We also investigated whether nonadherent patients differed from adherent patients in their beliefs about medications.

Methods: Forty-four individuals with type 2 diabetes and serious mental illness who were prescribed hypoglycemic and antipsychotic medications completed a cross-sectional assessment of medication beliefs and adherence for both medication types.

Results: Patients perceived a greater need for hypoglycemic versus antipsychotic medications; however, their beliefs were not associated with nonadherence to either medication type.

Conclusion: These results suggest that individuals with coexisting serious mental illness and type 2 diabetes have stronger convictions regarding the necessity of their diabetes medication for maintaining their health.

Keywords: nonadherence, antipsychotic medication, type 2 diabetes, medication beliefs, hypoglycemic medication, serious mental illness

\section{Introduction}

Nonadherence to antipsychotic medications is common in individuals with schizophrenia and other serious mental illness, with an estimated 50\% of individuals characterized as nonadherent. ${ }^{1}$ Nonadherence to antipsychotic medication has been linked with symptom relapse, worse prognosis, increased hospital use, and high health care costs. ${ }^{2-5}$

Patient attitudes towards antipsychotic medications are an important contributing factor in the decision to adhere to an antipsychotic medication regimen. ${ }^{6}$ Negative attitudes towards antipsychotic medication (eg, believing that one's body and mind are "controlled" by medication, or that one is "doped up" when adhering to antipsychotic prescriptions) are consistently related to nonadherence, both in cross-sectional ${ }^{7}$ and longitudinal ${ }^{8}$ studies. Using the Beliefs about Medication Questionnaire, ${ }^{9}$ Jónsdóttir et $\mathrm{al}^{10}$ found that patients with serious mental illness who were nonadherent to psychotropic medication of any type felt medication to be less necessary and expressed greater concerns about medications than adherent patients. Similarly, greater concern about the risks of antipsychotic use (measured with the Beliefs about Medication Questionnaire) was associated with greater nonadherence in a sample of individuals with schizophrenia or schizoaffective disorder who were prescribed either depot or oral antipsychotic medication. ${ }^{11}$

Individuals with serious mental illness are particularly susceptible to the development of chronic medical conditions, such as type 2 diabetes. ${ }^{12,13}$ Because medication 
is critical for the management of such conditions, a more in-depth understanding of beliefs about medications for chronic medical conditions and adherence in individuals with serious mental illness is needed. Medication attitudes have predicted adherence for individuals with chronic medical conditions and no history of mental illness. In a "chronic illness" sample, some of whom were diagnosed with diabetes, stronger beliefs about the necessity of medication for maintaining health were associated with better medication adherence, and greater concerns about the adverse consequences of medication were associated with poorer adherence. ${ }^{9}$

Recent research has demonstrated that the hypoglycemic medication adherence of individuals with coexisting serious mental illness and diabetes is better than that of diabetes patients with no history of mental illness, ${ }^{14,15}$ and that these two patient groups share similar attitudes regarding the necessity and risks of hypoglycemic medication. ${ }^{15}$ Despite the prevalence of coexisting medical conditions among persons with serious mental illness and the high rates of premature mortality in this population, no previous studies have compared the beliefs of individuals with serious mental illness regarding their medications for medical conditions, such as diabetes, to their beliefs about antipsychotic medications.

An understanding of differential medication beliefs and adherence can inform interventions to promote adherence and help individuals to self-manage multiple complex chronic conditions more effectively. To this end, within a well characterized cohort of patients with serious mental illness and type 2 diabetes, this study compared patients' beliefs about hypoglycemic medications with their beliefs about antipsychotic medications, evaluated the relationship between beliefs and nonadherence for both types of medication, and compared nonadherence with antipsychotic versus hypoglycemic medications. We hypothesized that beliefs about the necessity and risk of hypoglycemic medication use would be associated with nonadherence to hypoglycemic medication, and that beliefs about the necessity and risk of antipsychotic medication use would be associated with nonadherence to antipsychotic medication. Because no previous studies have compared beliefs about hypoglycemic medication with beliefs about antipsychotic medication, these analyses were exploratory in nature.

\section{Materials and methods}

\section{Study sample and setting}

The 44 participants in this study had taken part in an earlier investigation comparing the processes and outcomes of care for type 2 diabetes between 201 individuals with a coexisting serious mental illness and a comparison group without a psychiatric illness $(n=99)$. All participants had a medical chart diagnosis of type 2 diabetes, and were 18-65 years of age at time 1, English-speaking, and able to provide informed consent. Participants in the serious mental illness group had a medical chart diagnosis of schizophrenia, schizoaffective, bipolar, or major depressive disorder. A more detailed description of the recruitment strategies and assessment procedures is provided elsewhere. ${ }^{16}$

The 44 participants in the current study were further drawn from the 95/201 people (47\%) with a serious mental illness who completed a 5-year follow-up assessment of the original study. Among these 95, 90 (95\%) expressed an interest in participating in the current study on medication adherence and were screened for eligibility. To be included in the current study, participants had to be receiving one or more oral or injectable hypoglycemic medications prescribed routinely and at least one oral antipsychotic medication prescribed routinely. Among the 90 individuals considered for participation, 46 were not enrolled (39 did not meet eligibility criteria, four could not be reached during the study time frame, two had died, and one was in a nursing home). The remaining 44 (49\% of 90 ) were enrolled in the study. Compared with the individuals having serious mental illness who completed the 5-year follow-up assessment but who were not included in the current study, a larger proportion of participants in this study were diagnosed with schizophrenia rather than a mood disorder, and the participants in this study were younger than those who did not participate in this study. The groups did not differ on any other demographic, mental health-related, or diabetes-related characteristics. The institutional review board of the University of Maryland School of Medicine approved the study, and all participants provided written informed consent to be interviewed and permitted a review of their medical records.

\section{Data sources and measures}

Between January 2006 and July 2007, all participants met with research staff for approximately 60-90 minutes to complete an assessment of medication beliefs and adherence. We used the Beliefs about Medication Questionnaire: Specific Version (BMQ-Specific), ${ }^{9}$ to characterize patients' beliefs about the necessity of hypoglycemic and antipsychotic medications for controlling their illnesses and their concerns about the adverse consequences of taking the medications. Six of the 11 statements in the BMQ-Specific comprise a "Concerns" subscale and five statements comprise a "Necessity" subscale. One questionnaire was administered 
for all hypoglycemic medications, and another was administered for all antipsychotic medications prescribed. Respondents indicated their degree of agreement with the statements using a Likert scale ranging from 1 (strongly disagree) to 5 (strongly agree), with higher scores on the Necessity items indicating stronger beliefs about the necessity of antipsychotic or hypoglycemic medications and higher scores on the Concerns items indicating greater concerns about adverse effects. The BMQ-Specific has satisfactory psychometric properties for use in individuals with severe mental disorders, demonstrating acceptable internal reliability and test-retest reliability, ${ }^{17}$ as well as a relationship to related concepts of insight and illness perception ${ }^{17}$ and with psychotropic medication adherence in these patients. ${ }^{10,17}$

Participants were instructed to bring all currently prescribed medications, in either bottles or as a list. Research staff noted the name, dosage strength, and frequency of administration for all medications prescribed on a routine (ie, not as needed) basis. We then determined the total number of medications prescribed, the number of hypoglycemic medications (oral or insulin) prescribed, the number of antipsychotic medications prescribed, and their directions for administration.

Nonadherence to hypoglycemic medications and to antipsychotic medications was ascertained using the Brief Medication Questionnaire. ${ }^{18}$ Research staff interviewed participants about their medication use, and then compared participants' responses with the medications' directions for use. The definition of adherence specified by the developers of the Brief Medication Questionnaire was employed in the current study. Participants who reported stopping the medicine due to a late refill or other reason, missing any doses, or consuming greater than the prescribed amount during the past week were considered nonadherent to that particular medication.

\section{Data analysis}

To compare patients' beliefs about antipsychotic medications versus hypoglycemic medications, we conducted a series of paired $t$-tests, comparing the BMQ-Specific Necessity subscale score and Concerns subscale score for antipsychotic medications with their BMQ-Specific Necessity and Concerns subscale scores for hypoglycemic medications. Effect sizes are reported for these comparisons, correcting for dependence between means. ${ }^{19}$ Independent $t$-tests were used to compare beliefs about antipsychotic medications (BMQ-Specific Necessity and Concerns subscales) between antipsychoticnonadherent patients and antipsychotic-adherent patients.
The same statistical approach was used for hypoglycemic medications. McNemar's test (binomial approximation) was used to assess whether the group's self-reported nonadherence in the past week differed significantly between the two drug types.

\section{Results}

\section{Sample characteristics}

The demographic, clinical, and diabetes-related characteristics of the sample are shown in Table 1. A total of $70 \%(31 / 44)$ of study participants were diagnosed with a schizophrenia spectrum disorder and 30\% (13/44) with a major mood disorder. Virtually all participants (43/44) had seen a mental health care provider in the past 6 months. Five percent $(2 / 44)$ had been hospitalized for diabetes and $11 \%$ $(5 / 44)$ had been hospitalized for psychiatric reasons in the 6 months prior to assessment.

\section{Beliefs about antipsychotic versus hypoglycemic medications}

Individuals reported stronger beliefs about the necessity of their hypoglycemic medication versus their antipsychotic medication, as reflected in their higher scores on the BMQ Necessity subscale for hypoglycemic medications (mean $4.08 \pm 0.69)$ than for antipsychotic medications [mean $3.80 \pm 0.75 ; \mathrm{t}(43)=-2.00, P=0.05]$. The effect size $d$ of -0.31 indicates a small effect. There was a nonsignificant trend toward individuals having greater concerns about the overall risks of hypoglycemic medications versus antipsychotics, as reflected in their higher scores on the BMQ Concerns

Table I Demographic, clinical, and diabetes-related characteristics of sample $(n=44)$

\begin{tabular}{ll}
\hline Demographic characteristics & \\
Age (mean \pm SD), years & $5 I . I(9.3)$ \\
Gender, \% female & $55 \%(\mathrm{n}=24)$ \\
$\begin{array}{l}\text { Race, \% non-Caucasian } \\
\text { \% high school education or higher }\end{array}$ & $41 \%(\mathrm{n}=18)$ \\
$\begin{array}{l}\text { Diabetes-related characteristics } \\
\text { Duration of diabetes (mean } \pm \text { SD), years }\end{array}$ & $71 \%(\mathrm{n}=3 \mathrm{I})$ \\
$\begin{array}{l}\text { Total number of hypoglycemic medications } \\
\text { prescribed (mean } \pm \text { SD) }\end{array}$ & $12.8(6.4)$ \\
$\begin{array}{l}\text { Number of outpatient diabetes visits (mean } \pm \text { SD), } \\
\text { past } 6 \text { months }\end{array}$ & $1.8(0.8)$ \\
$\begin{array}{l}\text { Clinical characteristics } \\
\text { Total number of antipsychotic medications }\end{array}$ & $2.6(2.8)$ \\
$\begin{array}{l}\text { prescribed (mean } \pm \text { SD) } \\
\text { Total number of medical conditions diagnosed } \\
\text { (mean } \pm \text { SD) }\end{array}$ & $1.2(0.4)$ \\
$\begin{array}{l}\text { Total number of medications prescribed (mean } \pm \text { SD) } \\
\text { Abbreviation: SD, standard deviation. }\end{array}$ & $10.3(3.4)$ \\
\hline
\end{tabular}


subscale for hypoglycemic medications (mean $2.78 \pm 0.79$ ) than for antipsychotic medications [mean $2.61 \pm 0.77$, $\mathrm{t}$ $(43)=-1.83, P=0.07]$. The effect size $d$ of -0.27 indicates a small effect.

\section{Relationship between medication beliefs and nonadherence}

Neither beliefs about the necessity of antipsychotic medications nor concerns about their risks was associated with adherence to these agents. This is reflected in the similar scores on the BMQ Necessity subscale [mean $3.85 \pm 0.67$ versus mean $3.69 \pm 0.94 ; \mathrm{t}(42)=0.61, P=0.55]$ and BMQ Concerns subscale [mean $2.61 \pm 0.76$ versus mean $2.62 \pm 0.84 ; \mathrm{t}(42)=-0.03, P=0.98]$ for those individuals adherent versus nonadherent to antipsychotic medications, respectively.

Similarly for hypoglycemic medications, neither beliefs about the necessity of medications nor concerns about their risks was associated with adherence to these medications. This is reflected in the similar scores on the BMQ Necessity subscale [mean $4.22 \pm 0.49$ versus mean $3.70 \pm 1.00$; $\mathrm{t}(42)=1.72, P=0.11]$ and BMQ Concerns subscale [mean $2.73 \pm 0.75$ versus mean $2.92 \pm 0.91 ; \mathrm{t}(42)=-0.67, P=0.50]$ for those individuals adherent versus nonadherent to these medications, respectively.

\section{Relationship between antipsychotic and hypoglycemic nonadherence}

Individuals were no more likely to be nonadherent to their antipsychotic medications than to their hypoglycemic medications $(P=1.00)$. Eleven percent $(5 / 44)$ of the patients were nonadherent with both their hypoglycemic and antipsychotic medications, $16 \%$ (7/44) were nonadherent to hypoglycemic medication only, $18 \%(8 / 44)$ were nonadherent to antipsychotic medication only, and 55\% (24/44) were adherent to both medication types.

\section{Discussion}

This study is the first to find evidence that individuals with coexisting serious mental illness and a chronic medical condition, ie, type 2 diabetes, felt the medication for their chronic medical condition to be more necessary to their health than antipsychotic medication. This finding corresponds well with research demonstrating relatively good adherence to diabetes medication in individuals with serious mental illness diagnoses. ${ }^{14,15}$ When one considers the severe, sometimes irreversible, consequences of poorly managed diabetes, including blindness, cardiovascular disease, or the loss of a limb, such strong beliefs about the necessity of managing this illness are understandable. Furthermore, the immediate consequences of hypoglycemic medication nonadherence, such as polyuria and blurred vision, may be more readily apparent to the patient than the immediate consequences of nonadherence to antipsychotic medication, of which there may be none. The consequences of poor diabetes managment may also be somewhat more concrete and less subject to issues of insight and subjective impression than are the symptoms of mental illness.

The diagnostic composition of the sample in this study could have affected the results. Thirty percent of the individuals in the study were diagnosed with affective disorders, including treatment-refractory major depressive disorder and bipolar disorder. Although some antipsychotics are approved by the US Food and Drug Administration for treatment of these disorders, antipsychotics are possibly more often prescribed in conjunction with a mood stabilizer or an antidepressant, and may thus be perceived as less essential to long-term health by individuals with mood disorders. The difference in beliefs about the importance of hypoglycemic versus antipsychotic medications for future health could have been, in part, due to beliefs about the relative unimportance of antipsychotic medications held by those with a mood disorder. Future research involving a larger sample size should explore differences in medication beliefs among individuals carrying different serious mental illness diagnoses.

Contrary to the study hypotheses and in contrast with previous research, ${ }^{6-8,10,11}$ there was no significant relationship between medication beliefs and nonadherence for either type of medication. It is possible that our small sample could have precluded our ability to detect an association between medication beliefs and adherence. That said, it is worth noting that medication attitudes are only one of many factors affecting adherence. Although patient adherence is also affected by other factors, including medication costs, side effects, and cognitive impairments, in addition to attitudes held by the patient, evaluating the effects of these other factors on adherence was beyond the scope of this study.

Patients in this study were equally as likely to be adherent to their antipsychotic medication as to their hypoglycemic medication. Although past findings are mixed, ${ }^{20}$ the current results correspond with previous research suggesting no differences in adherence between psychotropic and somatic medications. ${ }^{21,22}$ Our findings may be related to the fact that over half of the patients in this study reported adherence to both medication types. This high rate of adherence may be 
a reflection of our use of self-report adherence data, which may have led to inflated estimates of medication adherence. ${ }^{23}$ However, a recent meta-analysis suggests that adherence estimates based on self-report do not appear to be grossly inflated. ${ }^{24}$ Furthermore, the study employed a very conservative definition of adherence, which could plausibly have led to fewer individuals categorized as adherent than found in studies using a more liberal definition.

This study sample was composed of those individuals willing to participate in follow-up from an earlier study of diabetes self-management and outcomes, and it is possible that individuals adherent to their medication regimens would more readily agree to the follow-up session than those who were nonadherent. This potential selection bias could diminish the generalizability of the results, because this subsample of patients may demonstrate greater adherence than the population of interest.

\section{Conclusion}

Limitations notwithstanding, this study presents noteworthy information regarding beliefs about medication not previously reported in the literature. The results of this study indicate that individuals with coexisting serious mental illness and type 2 diabetes are more convinced of the importance of managing their chronic medical condition than their mental illness.

\section{Acknowledgments}

This work was supported by a Brain and Behavior Research Foundation Young Investigator Award, a VA VISN 5 Mental Illness Research, Education, and Clinical Center pilot project grant, and a National Institute of Mental Health Research Career Award (K01 MH066009) to JAK. Writing of this manuscript was supported by the Office of Academic Affiliations, Advanced Fellowship Program in Mental Illness Research and Treatment, Department of Veterans Affairs.

\section{Disclosure}

The authors report no conflicts of interest in this work.

\section{References}

1. Dolder CR, Lacro JP, Leckband S, Jeste DV. Interventions to improve antipsychotic medication adherence: review of recent literature. J Clin Psychopharmacol. 2003;23:389-399.

2. Byerly MJ, Nakonezny PA, Lescouflair E. Antipsychotic medication adherence in schizophrenia. Psychiatr Clin North Am. 2007;30: 437-452.

3. Olfson M, Mechanic D, Hansell S, Boyer CA, Walkup J, Weiden PJ. Predicting medication noncompliance after hospital discharge among patients with schizophrenia. Psychiatr Serv. 2000;51:216-222.

4. Weiden PJ, Olfson M. Cost of relapse in schizophrenia. Schizophr Bull. 1995;21:419-429.
5. Wyatt RJ. Neuroleptics and the natural course of schizophrenia Schizophr Bull. 1991;17:325-351.

6. Lacro JP, Dunn LB, Dolder CR, Leckband SG, Jeste DV. Prevalence of and risk factors for medication nonadherence in patients with schizophrenia: a comprehensive review of recent literature. J Clin Psychiatry. 2002;63:892-909.

7. Garavan J, Browne S, Gervin M, Lane A, Larkin C, O’Callaghan E. Compliance with neuroleptic medication in outpatients with schizophrenia; relationship to subjective response to neuroleptics; attitudes to medication and insight. Compr Psychiatry. 1998;39:215-219.

8. Buchanan A. A two-year prospective study of treatment compliance in patients with schizophrenia. Psychol Med. 1992;22:787-797.

9. Horne R, Weinman J, Hankins M. The Beliefs about Medicines Questionnaire: the development and evaluation of a new method for assessing the cognitive representation of medication. Psychol Health. 1999;14:11-24.

10. Jónsdóttir H, Friis S, Horne R, Pettersen KI, Reikvam A, Andreassen OA. Beliefs about medications: measurement and relationship to adherence in patients with severe mental disorders. Acta Psychiatr Scand. 2009;119:78-84.

11. Patel MX, Zoysa N, Bernadt M, David AS. A cross-sectional study of patients' perspectives on adherence to antipsychotic medication: depot versus oral. J Clin Psychiatry. 2008;69:1548-1556.

12. Dixon L, Weiden P, Delahanty J, et al. Prevalence and correlates of diabetes in national schizophrenia samples. Schizophr Bull. 2000;26: 903-912.

13. Mukherjee S, Decina P, Bocola V, Saraceni F, Scapicchi P. Diabetes mellitus in schizophrenic patients. Compr Psychiatry. 1996;37: $68-73$.

14. Kreyenbuhl J, Dixon LB, McCarthy JF, Soliman S, Ignacio RV, Valenstein M. Does adherence to medications for Type 2 diabetes differ between individuals with versus without schizophrenia? Schizophr Bull. 2010;36:428-435.

15. Kreyenbuhl J, Leith J, Medoff DR, et al. A comparison of adherence to hypoglycemic medications between type 2 diabetes patients with and without serious mental illness. Psychiatry Res. 2011;188: 109-114.

16. Dixon LB, Kreyenbuhl JA, Dickerson FB, et al. A comparison of type 2 diabetes outcomes among persons with and without severe mental illness. Psychiatr Serv. 2004;55:892-900.

17. Beck E-M, Vogelin R, Wirtz M, Cavelti M, Kvrgic S, Vauth R. Do patients with schizophrenia distinguish between attitudes toward antipsychotic medication and pharmacotherapy in general? Validation of the Beliefs about Medication Questionnaire. J Nerv Ment Dis. 2012;200:33-43.

18. Svarstad BL, Chewning BA, Sleath BL, Claesson C. The Brief Medication Questionnaire: a tool for screening patient adherence and barriers to adherence. Patient Educ Couns. 1999;37:113-124.

19. Morris SB, DeShon RP. Combining effect size estimates in metaanalysis with repeated measures and independent-groups designs. Psychol Methods. 2002;7:105-125.

20. Piette JD, Heisler M, Ganoczy D, McCarthy JF, Valenstein M. Differential medication adherence among patients with schizophrenia and comorbid diabetes and hypertension. Psychiatr Serv. 2007;58:207-212.

21. Dolder CR, Lacro JP, Jeste DV. Adherence to antipsychotic and nonpsychiatric medications in middle-aged and older patients with psychotic disorders. Psychosom Med. 2003;65:156-162.

22. Pratt SI, Mueser KT, Driscoll M, Wolfe R, Bartels SJ. Medication nonadherence in older people with serious mental illness: prevalence and correlates. Psychiatr Rehabil J. 2006;29:299-310.

23. Velligan DI, Lam YW, Glahn DC, et al. Defining and assessing adherence to oral antipsychotics: a review of the literature. Schizophr Bull. 2006;32:724-742.

24. DiMatteo MR. Variations in patients' adherence to medical recommendations: a quantitative review of 50 years of research. Med Care. 2004;42:200-209. 
Patient Preference and Adherence

Dovepress

\section{Publish your work in this journal}

Patient Preference and Adherence is an international, peer-reviewed, open access journal focusing on the growing importance of patient preference and adherence throughout the therapeutic continuum. Patient satisfaction, acceptability, quality of life, compliance, persistence and their role in developing new therapeutic modalities and compounds to

optimize clinical outcomes for existing disease states are major areas of interest. This journal has been accepted for indexing on PubMed Central. The manuscript management system is completely online and includes a very quick and fair peer-review system. Visit http://www.dovepress.com/ testimonials.php to read real quotes from published authors.

Submit your manuscript here: http://www.dovepress.com/patient-preference-and-adherence-journal 